\title{
EMERGÊNCIA DE PLÂNTULAS DE Butia odorata (BARB. RODR.) NOBLICK EM CASA DE VEGETAÇÃOO ${ }^{1}$
}

\author{
Claudimar Sidnei Fior ${ }^{2}$, Paulo Vitor Dutra de Souza ${ }^{3}$ e Sergio Francisco Schwarz ${ }^{3}$
}

\begin{abstract}
RESUMO - Butia odorata é uma palmeira nativa do Rio Grande do Sul, Brasil, cujos frutos são utilizados na alimentação humana. O objetivo deste estudo foi testar a emergência de plântulas de $B$. odorata em casa de vegetação a partir de sementes e diásporos submetidos a diferentes procedimentos de superação de dormência. A escarificação através da abertura da cavidade embrionária das sementes permitiu emergência de $72 \%$, com tempo médio de 56 dias. A imersão dos diásporos em água por $18 \mathrm{~h}$ antes da semeadura favoreceu a emergência, porém o tempo médio atrasou para 323 dias. Sementes isoladas do endocarpo, porém não escarificadas, apresentaram $38 \%$ de emergência, com tempo médio de 319 dias. A emergência a partir de diásporos submetidos a $40^{\circ} \mathrm{C}$ por três semanas antes da semeadura não diferiu da emergência de sementes isoladas do endocarpo; no entanto, o tempo médio foi reduzido de 319 para 206 dias. A abertura da cavidade embrionária possibilitou o maior percentual de emergência de plântulas e menor tempo médio de emergência.
\end{abstract}

Palavras-chave: Dormência; Arecaceae; Opérculo.

\section{EMERGENCE OF Butia odorata (BARB.RODR.) NOBLICK SEEDLINGS IN GREENHOUSE}

\begin{abstract}
Butia odorata is a native palm tree from Rio Grande do Sul State, Brazil, with fruits used as food. The aim of this study was to test the emergence of seeds and diaspores under different procedures to dormancy breaking in greenhouse conditions. Scarification by opening of the embryonic cavity of the seed allowed the emergence of $72 \%$ in a mean time of 56 days. The immersion of the seeds in water for $18 \mathrm{~h}$ before to sowing increased the emergence but delayed the mean time to 323 days. Seeds isolated from the endocarp and not scarified presented $38 \%$ of germination in a mean time of 319 days. The emergence from diaspores submitted to $40^{\circ} \mathrm{C}$ for three weeks before sowing was not significantly different to emergence from seeds isolated from endocarp, however the mean time was reduced to 206 days. The opening of the embryonic cavity resulted in higher percentage of emergency, with significant lower mean time.
\end{abstract}

Keywords: Dormancy; Arecaceae; Operculum.

\section{INTRODUÇÃO}

Butia odorata (Barb.Rodr.) Noblick, conhecido popularmente como butiazeiro, é uma palmeira característica do Uruguai, ocorrendo também no Brasil apenas no Estado do Rio Grande do Sul. Desenvolve-se fundamentalmente sobre solos planos e inundáveis, embora também seja possível encontrá-lo em regiões serranas (GEYMONAT; ROCHA, 2009; LORENZI et al., 2010). Ciente da existência de dubiedades na identificação das populações de Butia spp., neste trabalho optou-se pela classificação proposta recentemente por Lorenzi et al. (2010). Em razão disso, na revisão bibliográfica e coleta de informações aqui apresentadas, tomou-se como critério o enquadramento da população citada em cada fonte pesquisada, de acordo com os locais de ocorrência de cada espécie, conforme descrição dos autores da referida classificação.

É uma espécie utilizada na alimentação, com estudos arqueológicos constatando que frutos de butiazeiros são utilizados por humanos há milênios, pois foram

\footnotetext{
${ }^{1}$ Recebido em 06.02.2013 aceito para publicação em 12.05.2013.

2 Jardim Botânico, Fundação Zoobotânica do Rio Grande do Sul. E-mail: <csfior@ufrgs.br>.

${ }^{3}$ Faculdade de Agronomia e Programa de Pós-Graduação em Fitotecnia da Universidade Federal do Rio Grande do Sul, Brasil. E-mail: <csfior@ufrgs.br>,<pvdsouza@ufrgs.br>e <schwarz@ufrgs.br>.
} 
encontrados caroços de frutos carbonizados em restos mortais de indígenas sepultados há 2.500 anos (CARDOSO, 1995).

Trabalhos têm demonstrado o grande potencial dos frutos de Butia spp. para fabricação de inúmeros produtos pela agroindústria (TONIETTO et al., 2009; GEYMONAT; ROCHA, 2009). No entanto, avanços têm sido impedidos devido à falta de conhecimento sobre a produção em escala e manejo de mudas (FIOR, 2011). Além disso, são inúmeros os casos de flagrantes de extração ilegal de exemplares adultos de butiazeiros para uso em paisagismo. Estima-se que alguns desses espécimes apresentem idade superior a 100 anos, o que descarta a possibilidade de terem sido cultivados para tal finalidade (ROSSATO, 2007; FIOR, 2011).

Diásporos de palmeiras podem possuir endocarpo relativamente espesso, com uma tampa de germinação, ou opérculo, que pode ser observado na testa ou endocarpo de algumas espécies. O embrião, relativamente pequeno e normalmente cilíndrico, é encontrado sob o opérculo (PÉREZ, 2009).

A germinação das sementes de palmeiras pode ser classificada em dois tipos: germinação remota e germinação adjacente. Na germinação das sementes do tipo remota, o eixo embrionário desenvolve-se a certa distância da semente. A primeira estrutura a emergir é chamada de pecíolo cotiledonar, que penetra o solo para, então, dar origem à raiz primária e à parte aérea da plântula (Figura 1). O cotilédone permanece no interior da semente, funcionando como órgão de condução de nutrientes do endosperma para a plântula em desenvolvimento, denominado haustório (MEEROW; BROSCHAT, 1991).

Para a maioria das palmeiras, alguns cuidados présemeadura possibilitam melhores resultados na germinação, entre eles: imersão em água para viabilizar a rápida embebição; estratificação em temperatura baixa ou alta, simulando a condição de um banco de sementes natural; escarificação, tanto pela imersão em ácido quanto corte ou lixamento do endocarpo; e retirada das sementes dos frutos para eliminação de um possível inibidor natural da germinação (ROBINSON, 2002). O uso de fitorreguladores, como o ácido giberélico, parece não apresentar efeito satisfatório para indução da germinação em muitas espécies de palmeiras (CARPENTER, 1988; LUZ et al., 2008; LOPES et al., 2011).

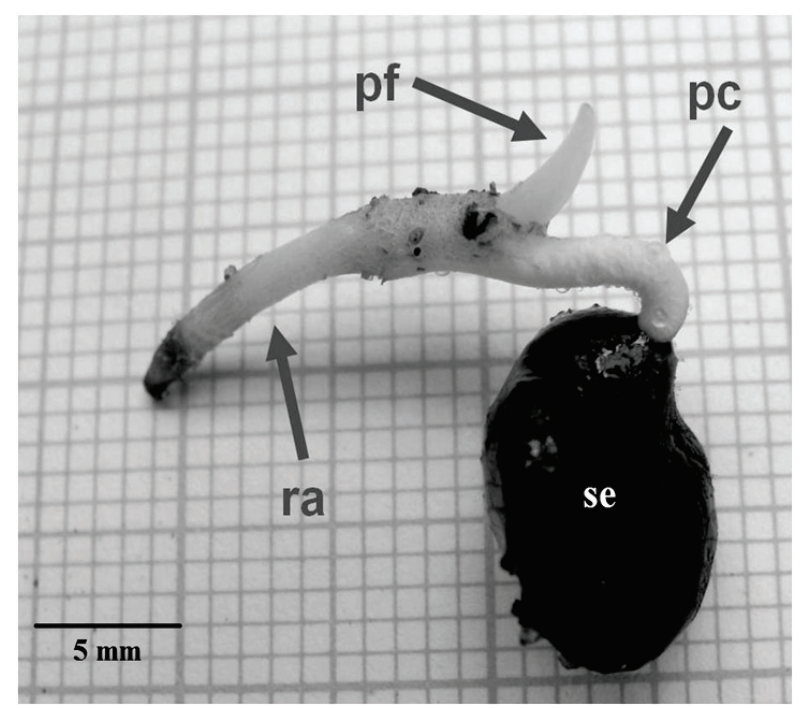

Figura 1 - Plântula de Butia odorata (pf: primeira folha; pc: pecíolo cotiledonar; ra: raiz primária; e se: semente).

Figure 1-Seedling of Butia odorata (pf: first leaf, pc: cotyledon petiole; ra: primary root; and se: seed).

De acordo com Pérez (2009), a germinação de palmeiras pode ser acelerada através da remoção do opérculo e, consequentemente, abertura da cavidade embrionária.

Fior et al. (2011) testaram a germinação in vitro de sementes de B. capitata e B. odorata submetidas a tratamentos de superação de dormência pela retirada do opérculo, abrindo parcial e totalmente a cavidade embrionária. Os resultados indicaram que a abertura parcial aumentou o percentual de germinação em até 25 pontos percentuais, em comparação com o tratamento com sementes não escarificadas. Já o tratamento com remoção total do opérculo da cavidade embrionária aumentou a germinação em mais de 80 pontos percentuais. O percentual de formação de plântulas foi igualmente alto nesse tratamento; em média, $92 \%$ das sementes germinadas formaram plântulas completas, em tempo médio de 29 dias a partir da semeadura. Resultados semelhantes foram obtidos pelos mesmos autores com sementes de $B$. odorata em ambiente de germinador, com temperatura constante de $25^{\circ} \mathrm{C}$.

O objetivo deste estudo foi testar diferentes procedimentos de superação de dormência na emergência de plântulas de B. odorata em casa de vegetação, a partir de sementes e diásporos. 


\section{MATERIAL E MÉTODOS}

Frutos maduros de B. odorata foram coletados no Município de Santa Maria, Depressão Central do Rio Grande do Sul. No dia seguinte à coleta, os frutos foram despolpados, secos ao ar sobre papel-filtro por $24 \mathrm{~h}$ e armazenados em embalagem de polietileno aberta sobre bancada de laboratório por 20 dias. Após esse período, realizou-se a determinação de teor de água através do método de diferença percentual de massa após a secagem em estufa a $105^{\circ} \mathrm{C}$ até massa constante (BRASIL, 2009).

Parte dos diásporos foi aberta com o auxílio de um torno de bancada, e as sementes foram isoladas, sendo durante esse procedimento descartadas as sementes danificadas por insetos ou microrganismos.

Em seguida, todos os diásporos e sementes utilizados no experimento foram desinfestados através de imersão por 2 min em etanol $70 \%$, seguido de 15 min em hipoclorito de sódio $1,5 \%$ de cloro ativo mais oito gotas $\mathrm{L}^{-1}$ de tensoativo polissorbato 20 (Tween $20^{\circledR}$ ). Para remoção dos resíduos dos agentes de desinfestação, as sementes foram enxaguadas três vezes com água deionizada autoclavada.

Os tratamentos de superação de dormência testados foram os seguintes: Sementes isoladas: sementes inteiras sem escarificação (SE); e sementes com opérculo removido, tendo a cavidade embrionária totalmente aberta de maneira a eliminar qualquer barreira mecânica ao desenvolvimento do embrião (AT); Diásporos: D-18 h: imersão por $18 \mathrm{~h}$ em água destilada, à temperatura ambiente entre 23 e $27^{\circ} \mathbf{C}$; e $\mathbf{D}-40{ }^{\circ} \mathbf{C}$ : pré-semeadura por três semanas, entre areia úmida, em caixas transparentes, sob temperatura constante de $40^{\circ} \mathrm{C}$, em germinador tipo Mangelsdorf, na ausência de luz. Logo após cada procedimento, sementes e diásporos foram distribuídos em bandejas de polietileno preto, preenchidas com uma camada de $6 \mathrm{~cm}$ de substrato composto por duas partes de fibra de mesocarpo de coco (pó-de-coco) e uma parte de areia média lavada (proporções volumétricas). O material foi mantido por 17 meses sobre bancada de concreto em casa de vegetação coberta por telha de fibra de vidro, sombreada internamente por tela de polietileno preta, com redução média da intensidade luminosa de $75 \%$, verificada através de um luxímetro analógico.

Ao final das avaliações, em cada experimento foram calculados: percentual de emergência (\%E), tempo médio de emergência (TME), determinado segundo Silva e
Nakagawa (1995), índice de velocidade de emergência (IVE), através da fórmula proposta por Silva e Nakagawa (1995) modificada conforme sugestão de Santana e Ranal (2004). A fim de equalizar as mensurações entre os testes com diásporos e sementes, os cálculos descritos tomaram por base a totalidade das sementes de cada tratamento, ou seja, para tratamentos com diásporos inteiros, os cálculos foram feitos sobre o número médio de sementes por diásporo, multiplicado pelo número de diásporos semeados.

O delineamento utilizado foi inteiramente casualizado, com quatro subamostras de 25 sementes ou diásporos por tratamento. Os dados foram submetidos ao teste de normalidade de Kolmogorov-Smirnov e ao teste de homocedasticidade de Levene. Em seguida, procedeu-se à análise de variância paramétrica e à comparação das médias pelo teste de DMS (5\%).

\section{RESULTADOS}

De acordo com o resultado do teste de determinação do teor de água, a umidade dos diásporos na ocasião da instalação do experimento era de $10,8 \%$.

Com a abertura total da cavidade embrionária, a emergência das plântulas iniciou-se aos 24 dias após a semeadura, sendo a emergência total de $72 \%$, com tempo médio de 56 dias. No tratamento em que os diásporos permaneceram por embebição durante $18 \mathrm{~h}$ antes da semeadura, o percentual de emergência foi igualmente alto, sem diferença estatística significativa. No entanto, o tempo médio foi muito superior (Tabela 1 e Figura 2).

O tratamento dos diásporos em temperatura de $40^{\circ} \mathrm{C}$ por três semanas, antes da semeadura, teve pouco efeito sobre a superação da dormência, indicando resposta intermediária no percentual de emergência e tempo médio, em comparação com o tratamento AT e os demais. A emergência das sementes isoladas, mas sem qualquer tratamento de superação de dormência (SE), apresentou percentual de emergência similar ao $\mathrm{D}-40{ }^{\circ} \mathrm{C}$, porém com tempo médio bem maior, semelhante ao tempo médio do tratamento D-18 h (Tabela 1).

O índice de velocidade de emergência apresentou variação muito similar ao tempo médio, indicando que a emergência ocorreu em maior velocidade no tratamento AT, seguido pelos D- $40{ }^{\circ} \mathrm{C}, \mathrm{D}-18 \mathrm{~h}$ e SE, e nos dois últimos não houve diferença significativa entre as médias (Tabela 1).

Revista Árvore, Viçosa-MG, v.37, n.7, p.503-510, 2013

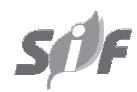


Tabela 1 - Emergência de Butia odorata em casa de vegetação. Tratamentos de quebra de dormência: SE: sementes isoladas dos endocarpos; AT: sementes isoladas dos endocarpos e escarificadas pelo método de abertura total da cavidade embrionária; D-18 h: diásporos inteiros mantidos submersos por 18 h em água destilada antes da semeadura; e D-40 ${ }^{\circ} \mathbf{C}$ : diásporos inteiros, com tratamento pré-semeadura de três semanas a $40{ }^{\circ} \mathrm{C}$, seguido de $25^{\circ} \mathrm{C}$.

Table 1 - Emergency of Butia odorata under treatments of dormancy breaking in greenhouse: SE: seed isolation from the endocarp; $\boldsymbol{A T}$ : seed isolation and scarification by full opening of the embrionary cavity; $\boldsymbol{D}-\mathbf{1 8} \boldsymbol{h}$ : diaspore immersion for 18 hours in distilled water before sowing; $\boldsymbol{D}-\mathbf{4 0}{ }^{\circ} \mathrm{C}$ : whole diaspore submission to pre-sowing by three weeks in continuous $40^{\circ} \mathrm{C}$, followed by $25^{\circ} \mathrm{C}$.

\begin{tabular}{cccc}
\hline Tratamento & $\begin{array}{c}\text { Percentual de } \\
\text { emergência }\end{array}$ & $\begin{array}{c}\text { Tempo médio de } \\
\text { emergência (dias) }\end{array}$ & $\begin{array}{c}\text { Índice de velocidade } \\
\text { de emergência }\end{array}$ \\
\hline SE & $38,0 \mathrm{~b}^{*}$ & $319,3 \mathrm{c}$ & $0,0040 \mathrm{c}$ \\
$\mathrm{AT}$ & $72,0 \mathrm{a}$ & $55,7 \mathrm{a}$ & $0,0233 \mathrm{a}$ \\
$\mathrm{D}-18 \mathrm{~h}$ & $67,2 \mathrm{a}$ & $323,0 \mathrm{c}$ & $0,0031 \mathrm{c}$ \\
$\mathrm{D}-40^{\circ} \mathrm{C}$ & $45,0 \mathrm{~b}$ & $206,0 \mathrm{~b}$ & $0,0069 \mathrm{~b}$ \\
$\mathrm{CV}(\%)$ & 20,56 & 5,73 & 10,39 \\
Valor $\mathrm{P}$ & $<0,01$ & $<0,01$ & $<0,01$ \\
\hline
\end{tabular}

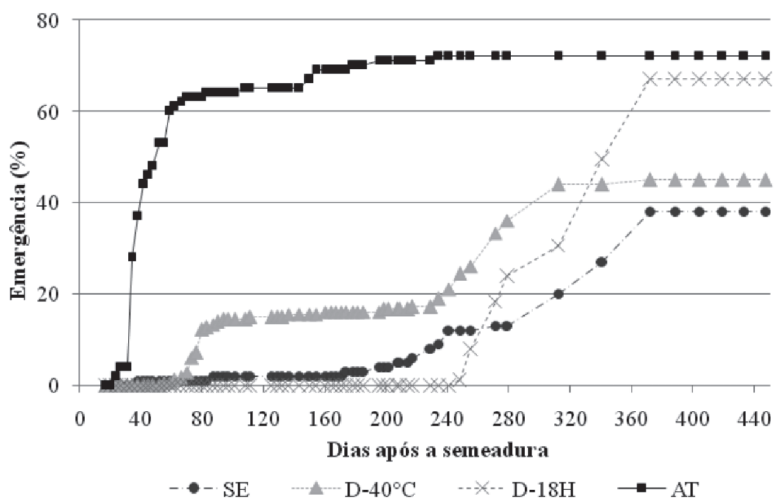

Figura 2 - Emergência de Butia odorata em casa de vegetação a partir de diásporos submetidos aos tratamentos de superação de dormência: $\mathbf{S E}$ : sementes isoladas dos endocarpos; AT: sementes isoladas dos endocarpos e escarificadas pela abertura total da cavidade embrionária; D-18 h: diásporos inteiros imersos por $18 \mathrm{~h}$ em água destilada; e $\mathbf{D}-\mathbf{4 0}{ }^{\circ} \mathbf{C}$ : diásporos inteiros tratados por três semanas a $40^{\circ} \mathrm{C}$, seguido de $25^{\circ} \mathrm{C}$ constantes.

Figure 2 - Emergency of Butia odorata diaspores submitted to treatments of dormancy breaking in greenhouse: $\boldsymbol{S E}$ : seed isolation from the endocarp; $\boldsymbol{A T}$ : seed isolation and scarification by full opening of the embrionary cavity; D-18h: diaspore immersion for 18 hours in distilled water before sowing; and $\mathrm{D}-40^{\circ} \mathrm{C}$ : whole diaspore submission to pre-sowing by three weeks in continuous $40^{\circ} \mathrm{C}$, followed by $25^{\circ} \mathrm{C}$.

A temperatura no interior da casa de vegetação manteve-se entre 10 e $24{ }^{\circ} \mathrm{C}$ nos meses de inverno e de 18 a $42,6^{\circ} \mathrm{C}$ no verão, variando pouco em relação à temperatura do ambiente externo (Figura 3 ).

Revista Árvore, Viçosa-MG, v.37, n.7, p.503-510, 2013

\section{DISCUSSÃO}

Carpenter (1988) e Fior et al. (2011) obtiveram entre 74 e $90 \%$ de germinação de embriões de Butia spp. in vitro, em meio de cultivo sem fitorreguladores, sob temperatura de $25^{\circ} \mathrm{C}$. Esses resultados sugeriram que a temperatura elevada não é determinante para o desenvolvimento do embrião, durante a germinação. Essa hipótese também foi levantada por Ribeiro et al. (2011) a partir de testes realizados com desenvolvimento in vitro de embriões de B. capitata. Esses autores concluíram que a dormência na espécie está relacionada com fatores externos ao embrião. Da mesma forma, os resultados deste estudo apontaram para essa hipótese, pois os embriões das sementes com poucos dias após a coleta mostraram-se aptos a germinar após a remoção do opérculo, sem que fosse necessário tratamento para superação de uma suposta dormência do embrião.

Em estudo realizado com Pritchardia remota Becc., palmeira endêmica do Hawaii, a remoção do opérculo reduziu pela metade o tempo médio de germinação (PÉREZ; CRILEY, 2008). Esses autores consideraram ainda que há necessidade de condição favorável de umidade, a fim de hidratar o embrião adequadamente para que seja possível o deslocamento natural do opérculo, o que explicaria o período de dormência relatado para a espécie, atribuindo, nesse caso, dormência fisiológica às suas sementes. Este não parece ser o caso da espécie $B$. odorata, pois diante dos resultados deste trabalho verificou-se que, mesmo hidratando os diásporos antes da semeadura e mantendo a umidade 


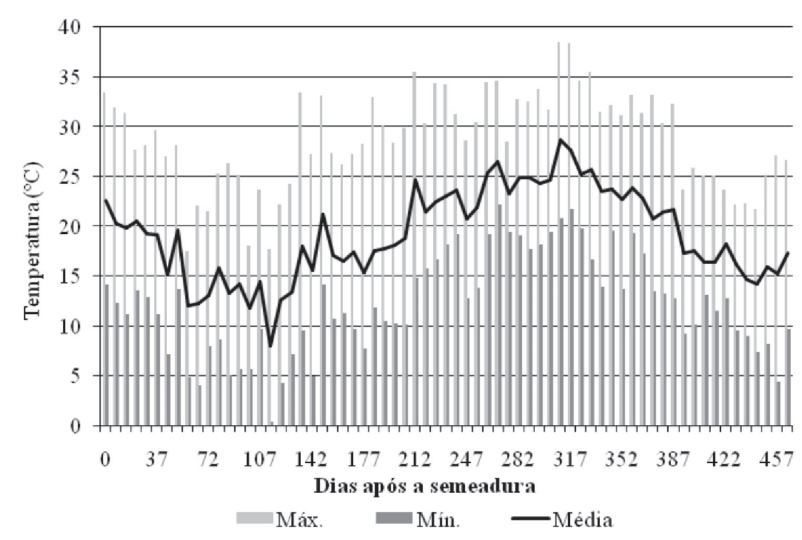

Figura 3 - Temperaturas máximas e mínimas absolutas e médias semanais do ambiente próximo à casa de vegetação onde foi conduzido o experimento de semeadura de Butia odorata (Instituto Nacional de Meteorologia INMET ( $8^{\circ}$ Distrito de Meteorologia Porto Alegre).

Figure 3-Maximum, minimum and mean weekly temperatures recorded for the outdoor environment next to the greenhouse wherein Butia odorata seeds were sown to the germination assay (Instituto Nacional de Meteorologia INMET, 8o Distrito de Meteorologia - Porto Alegre).

do substrato na sementeira, pode demorar muito para a germinação ocorrer ou, até mesmo, não acontecer.

Comparando emergência em casa de vegetação sem controle de temperatura (variação entre 23 e 38 ${ }^{\circ} \mathrm{C}$ ), Broschat (1998) verificou que sementes de $B$. capitata removidas do endocarpo apresentam resultados muito superiores, quando comparados com a semeadura de endocarpos inteiros, mesmo após o seu armazenamento por 150 dias a $23^{\circ} \mathrm{C}$. Nesse sentido, Lopes et al. (2007) mencionaram que o endocarpo limita a absorção de água pelas sementes, sugerindo tratar-se de uma forma de dormência exógena e que a remoção do endocarpo favorece a absorção de água.

Os resultados deste estudo apontaram que a superação da dormência das sementes de $B$. odorata não está relacionada apenas à presença do endocarpo, uma vez que o tratamento com sementes isoladas, porém sem escarificação, apresentou germinação inferior à dos demais tratamentos e significativamente diferente do tratamento em que as sementes foram isoladas e escarificadas (Tabela 1). Esses dados são corroborados por Broschat (1998), o qual comparou a emergência de plântulas de $B$. capitata a partir de sementes isoladas e endocarpos inteiros semeados logo após a coleta e, também, depois de 150 dias de armazenamento a $23^{\circ} \mathrm{C}$. Os percentuais de germinação foram igualmente baixos para os tratamentos.

Ao que a maioria dos trabalhos indica, a presença do endocarpo não dificulta a hidratação da semente. O incremento nos percentuais de germinação de sementes previamente isoladas dos endocarpos pode estar relacionado com possível escarificação involuntária, aleatória e não perceptível imposta às sementes no momento da quebra do caroço. Outro fator a ser considerado é que, diferentemente das sementes de muitas espécies, a testa das sementes das palmeiras parece não afetar a permeabilidade à água. De acordo com Gong et al. (2005), em sementes de Phoenix dactylifera L. foi verificado que as células da testa apresentam paredes finas, o que não seria impedimento para a absorção de água durante a germinação.

Carpenter et al. (1993) testaram métodos de escarificação mecânica de sementes de Rhapidophyllum hystrix (Pursh) H. Wendl. \& Drude, desde sementes sem escarificação, sementes com exposição do endosperma em região distante do embrião, remoção de parte do opérculo até a abertura total da cavidade embrionária pela remoção do opérculo. Pelos resultados, verificaram que a remoção total do opérculo permitiu, em média, $98 \%$ de germinação, com tempo médio de 1,3 semana. A estratificação das sementes por 12 meses a $5^{\circ} \mathrm{C}$, com umidade relativa do ar de $100 \%$, não alterou significativamente o percentual de germinação, tampouco o tempo médio de germinação. De acordo com os resultados obtidos por esses autores, há indicativos de ocorrência de dormência física imposta pelas estruturas da semente.

Carpenter (1988) e Schlindwein (2012) demonstraram o efeito positivo da exposição de sementes de $B$. capitata e $B$. odorata, respectivamente, a temperaturas altas $\left(40^{\circ} \mathrm{C}\right)$ em tratamento pré-semeadura, obtendo elevados percentuais de germinação in vivo. Neste estudo, tratamento semelhante com as sementes de $B$. odorata influenciou muito pouco a germinação, distinguindo-se dos resultados daqueles autores para as espécies mencionadas. De acordo com Hussey (1958), para a espécie Elaeis guineensis L. o regime térmico de $40^{\circ} \mathrm{C}$ nas primeiras quatro semanas após a semeadura, associado a ambiente com saturação de oxigênio no ar (100\% de $\mathrm{O}_{2}$ ), viabilizou índices de germinação muito superiores aos obtidos com o tratamento em que as sementes foram submetidas apenas ao tratamento térmico. Assim, 
pode-se considerar que o efeito dos microambientes das câmaras de germinação, ou até mesmo dos recipientes de semeadura, possa resultar em diferentes concentrações de oxigênio, o que explicaria as diferenças encontradas entre os estudos utilizando o mesmo tratamento.

As células do endosperma, incluindo a região micropilar, apresentam-se vivas e com paredes espessadas. No entanto, há uma região delimitada na cavidade embrionária, estendendo-se através do endosperma micropilar para a periferia, na qual as células têm paredes finas. Essas células formam um círculo imediatamente subjacente ao sulco da testa que delimita o opérculo. No momento da germinação ocorre o desenvolvimento do embrião, fazendo com que o opérculo seja empurrado para fora, ao que tudo indica devido à ruptura dos tecidos com células de paredes mais finas (GONG et al., 2005).

Sementes de muitas espécies têm a germinação viabilizada pelo enfraquecimento dos tecidos que circundam o embrião, permitindo, dessa forma, o alongamento da radícula. A redução da resistência mecânica imposta pelo endosperma é provocada pela ação de enzimas, como a beta mananase (BEWLEY, 1997; BORGES et al., 2004; SILVAet al., 2004). No entanto, de acordo com os resultados de Wang et al. (2004) e Gong et al. (2005), para muitas espécies, incluindo arecáceas, a ação dessa enzima nas células do endosperma micropilar restringe-se à mobilização de reservas após a germinação, o que não parece estar relacionado com a superação de dormência da semente.

Comparando os dados de emergência dos tratamentos SE, D-18 h e D-40 ${ }^{\circ} \mathrm{C}$ (Figura 2) com as temperaturas ambientais do período (Figura 3), percebeu-se que a maior emergência ocorreu exatamente após a elevação das temperaturas máximas, o que sugere que essa condição teve estímulo semelhante ao proporcionado pelo tratamento AT, elevando consideravelmente o percentual de emergência. Contudo, não fica claro qual o mecanismo desencadeado para que ocorra a germinação das sementes de B. odorata, assim como de outras espécies de palmeiras aqui mencionadas, que, aparentemente, apresentam comportamentos semelhantes, quando submetidas aos tratamentos de superação de dormência. No entanto, o que se pode concluir é que a dormência dessas sementes é amenizada naturalmente após determinado período com condições ambientais específicas, as quais promovem a ruptura da barreira física imposta pelos tecidos que compõem o endosperma micropilar e a sustentação do opérculo da semente.

Apesar de ter possibilitado elevado percentual de emergência em tempo reduzido, o método de abertura mecânica da cavidade embrionária é um processo trabalhoso e um tanto oneroso para um sistema de produção comercial de mudas. Por isso, há necessidade de mais estudos, de forma a identificar metodologia mais adequada para atender satisfatoriamente a esse elo da cadeia de produção de mudas.

Como alternativa, devem ser testadas substâncias, como enzimas, que degradam as camadas de tecidos envolvidas na constituição do opérculo, mesmo sem isolamento das sementes dos endocarpos, o que facilitaria o processo e dispensaria várias etapas, desonerando a produção de mudas. Salienta-se, portanto, a necessidade de estudos histológicos que permitam identificar a composição dos tecidos celulares que compõem o opérculo e o distinguem do embrião, para, então, definir possíveis substâncias a serem utilizadas para sua degradação, mantendo íntegros os tecidos essenciais para a germinação e desenvolvimento da plântula.

\section{CONCLUSÕES}

A abertura da cavidade embrionária pela remoção do opérculo é o tratamento que possibilita a obtenção do maior percentual de plântulas emergidas, além do menor tempo médio para emergência.

A emergência das plântulas nos demais tratamentos ocorreu de forma mais intensa após a elevação da temperatura ambiente.

\section{AGRADECIMENTOS}

Os autores agradecem à Fundação de Amparo à Pesquisa do Estado do Rio Grande do Sul (FAPERGS) e ao Conselho Nacional de Desenvolvimento Científico e Tecnológico (CNPq) pelo apoio financeiro para a realização do estudo.

\section{REFERÊNCIAS}

BEWLEY, J. D. Breaking down the walls - a role for endo-â-mannanase in release from seed dormancy? Trends in Plant Science, v.2, n.12, p.464-469, 1997. 
BORGES, E. E. L. et al. Alterações fisiológicas em sementes de Tachigalia multijuga (Benth.) (mamoneira) relacionadas aos métodos para a superação da dormência. Revista Árvore, v.28, n.3, p.317-325, 2004.

BRASIL. Ministério da Agricultura, Pecuária e Abastecimento. Regras para análise de sementes. Brasília: 2009. 395p.

BROSCHAT, T. K. Pindo palm (Butia capitata) seed germination revisited. TropicLine -

Horticulture Newsletter of the University of Florida Fort Lauderdale Research \& Education Center, v.10 n.34,1998. Disponível em: <http://flrec.ifas.ufl.edu/ pdfs/TropicLine/TropicLine_10-3-4.pdf $>$. Acesso em: 29 maio 2012.

CARDOSO, M. C. El palmar, la palma y el butiá. Montevideo: Productora Editorial, 1995. 23p. (Fichas Didácticas, 4.)

CARPENTER, W. J. Seed after-ripening and temperature influence in Butia capitata germination. Hort Science, v.23, n.4, p.702-703, 1988.

CARPENTER, W. J.; OSTMARK, E.R.; CORNELL, J.A. Embryo cap removal and high-temperature stimuli rapid germination of needle palm seeds. Hortscience, v.28, n.9, p.904-907, 1993.

FIOR, C. S. et al. Superação de dormência em sementes de Butia capitata. Ciencia Rural, v.41, n.7, p.1150-1153, 2011.

FIOR, C. S. Propagação de Butia odorata (Barb. Rodr.) Noblick \& Lorenzi. 2011. 184f. Tese (Doutorado em Fitotecnia) -

Universidade Federal do Rio Grande do Sul, Porto Alegre, 2011.

GEYMONAT, G.; ROCHA, N. M'botiá. Ecosistema único en el mundo. Castillos: Casa Ambiental, 2009. 405p.

GONG, X. et al. The emergence of embryos from hard seeds is related to the structure of the cell walls of the micropylar endosperm, and not to endo- $\beta$-mannanase activity. Annals of Botany, v.96, n.7, p.1165-1173. 2005.
HUSSEY, G. An analysis of the factors controlling the germination of the seed of oil palm, Elaeis guineensis (Jacq.). Annals of Botany, v.22, n.2, p.259-284, 1958 .

LOPES, P. S. N. et al. Absorção de água em sementes de coquinho-azedo. Revista Brasileira de Agroecologia, v.2, n.2, p.787-790, 2007.

LOPES, P. S. N. et al. Tratamentos físicos e químicos para superação de dormência em sementes de Butia capitata (Martius) Beccari. Pesquisa Agropecuária Tropical, v.41, n.1, p.120-125, 2011.

LORENZI, H. et al. Flora brasileira: Arecaceae (Palmeiras). Nova Odessa: Instituto Plantarum, 2010. 367p.

LUZ, P. B. et al. Germinação de sementes de palmeiraráfia: efeito de tratamentos pré-germinativos. RevistaÁrvore, v.32, n.5, p.793-798, 2008.

MeERoW, A.W.; Broschat, T. K. Palm seed germination. Gainesville: University of Florida, 1991. 9p.(Institute of Food and Agricultural Sciences, University of Florida Cooperative Extension Service Bulletin, 274).

PÉREZ, H.E.; CRILEY, R.A. Promoting germination in dormant seeds of Pritchardia remota (Kuntze) Beck., an endangered palm endemic to Hawaii. Natural Areas Journal, v.28, n.3, p.251-260, 2008.

PÉREZ, H. E. Promoting germination in ornamental palm seeds through dormancy alleviation. Hort Technology - American Society for Horticultural Science, v. 19, n.4, p.682-685, 2009.

RIBEIRO, L.M. et al. Germinação de embriões zigóticos e desenvolvimento in vitro de coquinhoazedo. Revista Ceres, v.58, n.2, p.133-139, 2011.

ROBINSON, M. L. Cultivated palm seed germination. SP-02-09 University of Nevada. 2002. Disponível em: <http://www.unce.unr.edu/ publications/files/ho/2002/sp0209.pdf > . Acesso em: 29 maio 2012.

ROSSATO, M. Recursos genéticos de palmeiras do gênero Butia do Rio Grande do Sul. 2007. 136f. Tese (Doutorado em Agronomia) Universidade Federal de Pelotas, Pelotas, 2007.

Revista Árvore, Viçosa-MG, v.37, n.7, p.503-510, 2013 
SANTANA, D. G.; RANAL, M.A. Análise da germinação - um enfoque estatístico. Brasília: Universidade de Brasília, 2004. 248p.

SCHLINDWEIN, G. Implicações ecológicas da dormência de sementes de Butia odorata (Arecaceae). 2012. 132f. Tese (Doutorado em Ciências) - Programa de Pós-Graduação em Ecologia, Instituto de Biociências, Universidade Federal do Rio Grande do Sul, Porto Alegre, 2012.

SILVA, E. A. A. et al. Abscisicacid controls embryo growth potential and endosperm capweakening duringcoffee (Coffea arabica $c v$. Rubi)

seedgermination. Planta, v.220, n.2, p.251-261, 2004.
SILVA, J. B. C.; NAKAGAWA, J. Estudos de fórmulas para cálculo de germinação. Informativo ABRATES, v.5, n.1, p.62-73, 1995.

TONIETTO, A.; SCHLINDWEIN, G.; TONIETTO, S. M. Usos e potencialidades do butiazeiro. Porto Alegre: Fepagro, 2009. 28p. (Circular Técnica, 26).

WANG, A.; JIERAN, L.; BEWLEY, J. D. Molecular cloningand characterization of an endo-âmannanase gene expressedin the lettuce endosperm following radicle emergence. Seed Science Research, v.14, n.3, p.267-276, 2004. 